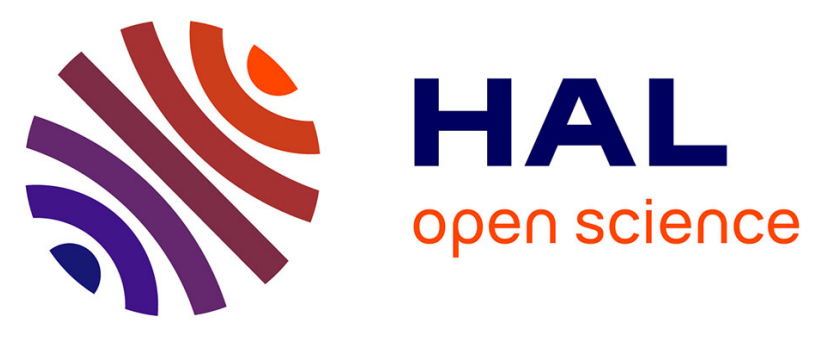

\title{
Negative wound therapy to manage large-for-size liver graft mismatch
}

\author{
Raffaele Brustia, Fabiano Perdigao, Ailton Sepulveda, Astrid Schielke, \\ Filomena Conti, Olivier Scatton
}

\section{- To cite this version:}

Raffaele Brustia, Fabiano Perdigao, Ailton Sepulveda, Astrid Schielke, Filomena Conti, et al.. Negative wound therapy to manage large-for-size liver graft mismatch. Clinics and Research in Hepatology and Gastroenterology, 2015, 39 (5), pp.552-554. 10.1016/j.clinre.2015.02.009 hal-02301957

\section{HAL Id: hal-02301957 https: / hal.sorbonne-universite.fr/hal-02301957}

Submitted on 30 Sep 2019

HAL is a multi-disciplinary open access archive for the deposit and dissemination of scientific research documents, whether they are published or not. The documents may come from teaching and research institutions in France or abroad, or from public or private research centers.
L'archive ouverte pluridisciplinaire HAL, est destinée au dépôt et à la diffusion de documents scientifiques de niveau recherche, publiés ou non, émanant des établissements d'enseignement et de recherche français ou étrangers, des laboratoires publics ou privés. 


\section{Negative Wound Therapy to manage large-for-size liver graft mismatch.}

Raffaele BRUSTIA, MD**; Fabiano PERDIGAO, MD*; Ailton SEPULVEDA, MD*; Astrid SCHIELKE, MD*; Filomena CONTI, MD, PhD*§; Olivier SCATTON, MD, PhD**.

* Department of Hepatobiliary and liver transplantation surgery, Hôpital Pitié-Salpêtrière, Assistance Publique-Hôpitaux de Paris, France.

** Université Pierre et Marie Curie, Paris, France

Corresponding author: Olivier SCATTON

Department of HPB surgery and liver transplantation Hôpital Pitié-Salpêtrière

47-83 Boulevard de l’ Hôpital

Paris 75013

Tel: $+33(1) 42.17 .56 .52$

Fax: +33 (1) 42.17.56.17

E-mail: olivier.scatton@gmail.com

\section{CLINICAL CHALLENGES}

Key words: Large-for-size liver graft; liver transplantation; Complications; Donor risk; Liver transplantation outcome; Graft Size Mismatch; Negative Wound Therapy; Alternative solutions; Delayed wound closure; Vacuum therapy; Wound Vacuum Therapy.

Abbreviations: LFS Large-for-Size, CT Computed Tomography, POD Post Operative Day, LT Liver Transplantation, LDLT Living Donor Living Transplantation.

Word count: 967

The authors declare no conflict of interest 
Advances in matching optimal liver volume have been done in LDLT, but not enough in deceased whole liver transplantation: excess in one sense or the other can lead to severe consequences. While small-for-size (SFS) is a well-known and preventable syndrome, no standard methods exist to predict large size mismatch, and their consequences. Large-forsize (LFS) grafts are defined as Graft-to-Recipient-Weight-Ratio (GWRW) $>4 \%(1)$ in pediatric LDLT or $>2.5 \%(2)$ in adult liver transplantation. An index integrating donor and receiver body surface area (BSAi) has recently defined LFS as a BSAi>1.24 (3). Consequences of LFS graft are highly variable, including high AST/ALT peak, respiratory failure, graft compression and necrosis, and retransplantation (2-5). Hazards ratio of graft failure with BSAi superior to 1.24 is $1.066(95 \% \mathrm{Cl} 1.006-1.130)$ (3).

But what does really happen "inside" a LFS graft? And what solutions can be envisioned?

\section{Patient 1}

A 61-y old woman $(49 \mathrm{~kg} 145 \mathrm{~cm})$, was admitted for fulminant hepatic failure on B viral infection: according to King's College Criteria (age $>40-y$, bilirubin $>300 \mu \mathrm{mol} / \mathrm{L}$ during 3 weeks before hepatic coma and INR > 3.5) she underwent an emergency LT with a whole $1660 \mathrm{gr}$ liver graft, issued from a $166 \mathrm{~cm} 76 \mathrm{~kg}$ deceased donor. Due to the large graft (GWRW 3.38\% and BSAi 1.33), excessive suture traction on aponevrosis during closure and concomitant increase in ventilatory pressure, abdominal closure was delayed after 6 days of Negative Wound Therapy (NWT). Postoperative course was characterized by transient renal failure requiring dialysis, abdominal wall hematoma and undetermined anaemia. She was discharged on POD 51, and followed as outpatient. Six months after the LT, she is in excellent clinical conditions (Table 1).

\section{Patient 2}


A $24-y$ old woman $(48 \mathrm{~kg} 168 \mathrm{~cm})$ underwent a transplant for primary sclerosing cholangitis with a right liver graft issued by a split with paediatric team. LT was complicate by an intraoperative hepatic artery thrombosis, which led - despite efforts - to a primary graft dysfunction. Emergency re-listing allowed retransplantation 48 hours later, with a whole 1443 gr liver graft issued from a $165 \mathrm{~cm} 68 \mathrm{~kg}$ donor. Given the size mismatch (GWRW 3.01\%, with BSAi 1.14) and excessive traction on abdominal wall sutures with no need to increase ventilatory pressure, elective skin closure was possible after 4 days of temporary closure on a NWT, to reduce intra-abdominal pressure. During the hospitalization she developed a rectus abdominis hematoma requiring surgical revision and a surgical site infection. She was discharged on POD 24 and followed as outpatient. After 3 months, she is in good clinical condition (Table 1).

\section{What's inside?}

Transaminases peaks in LFS are the consequence of graft compression, which can be documented by imaging. Both patients received a first CT scan during the first two weeks, a second scan one month after LT, and a third scan 3 or 6 months later. In both patients localized necrosis, mainly concentrated in the right posterior sector, progressively reduced

(Fig. 1) with no consequences and no need of surgical management. While GWRW $>2.5 \%$ predicted in both cases LFS, BSAi failed in patient $n^{\circ} 2$ (Table 1 ).

\section{Technical consideration}

Large grafts are difficult to implant because of steric hindrance due to the unexpandable limits of abdominal cavity (musculoskeletal cage, diaphragm, vertebral column). This can generate problems during cava anastomosis and can be potentially responsible for poor alignment of inflow and outflow structures (4). Technical solutions aim at changing either the "content" or the "container". The only ways to change the Liver Graft are its reduction or 
Split. If the latter is sometimes still considered in pediatric LT, graft reduction has little or place in adult LT: considered the need to expand the pool graft - a greater effort (in terms of timely planning, matching the good receiver, logistic, cold ischemia time) should rather be devoted to ensure a split.

Also some solutions exist to enhance the "container"- (receiver)'s tolerance to a LFS graft. Among them, the vena cava replacement is a technical alternative to avoid the receiver's compression in comparison to the piggyback technique (2). It should however be use with caution because of hemodynamic and renal tolerance.

A graft compression resulting from a direct wound closure can lead to insufficient blood supply as well as to graft necrosis caused by the direct pressure on the liver parenchyma (4, 5) as showed in Fig. 1. Wound closure is sometimes possible directly on prosthetic material, or can be delayed managing the open abdomen with sterile dressing (5). In the two reported cases we choose to use a strategy derived from trauma surgery to deal with open abdomen: NWT is today considered the evolution of "Bogota Bag" (6). The idea is to aseptically cover the abdominal wound with foam or gauze dressing and seal with an occlusive drape, without any tension. A vacuum pump connected with suction tubes can apply a negative pressure ranging from $-50 \mathrm{mmHg}$ to $-125 \mathrm{mmHg}$. The main advantage is the optional closure of the abdomen even if neither aponevrosis nor skin closure is possible: hollow viscera are protected by a special microporotic vicryl/plastic bag, which separates the bowel from the aspirative system. The either intermittent or continuous negative pressure can be set and modified depending on the evolution and kept as low as possible to avoid any bowel barotrauma. Changed aseptically every $48-72 \mathrm{~h}$ up-to three times, the frank reduction of visceral and parietal edema as well as the increase of local blood flow allowed us to realize an elective wound closure. An high postoperative AST/ALT peak was the only complication 
(Table 1), and it is consistent with clinical and experimental $(2,7)$ findings reported in the literature among LFS grafts.

\section{Conclusion}

In conclusion no standard and simple method exists to correctly match deceased donor grafts to avoid LFS. In case of a mismatch, technical tricks as vena cava replacement or delayed wound closure through NWT are good alternatives to minimize graft compression and necrosis. If such event are encountered, close clinical and imaging monitoring follow-ups allow a conservative treatment, with good results.

\section{REFERENCES}

(1) Kasahara M, Sakamoto S, Umeshita K et al. Effect of graft size matching on pediatric living-donor liver transplantation in Japan. Exp Clin Transplant 2014; suppl 1:1-4.

(2) Levesque E, Duclos J, Ciacio O, et al. Influence of larger graft weight to recipient weight on the post-liver transplantation course. Clin Transplant 2013;27:239-247.

(3) Fukazawa K, Yamada Y, Nishida S, et al. Determination of the safe range of graft size mismatch using body surface are index in deceased liver transplantation. Transpl Int. 2013;26:724-33.

(4) Reddy MS, Varghese J, Venkataraman J, Rela M. matching donor to recipient in liver transplantation : relevance in clinical practice. World J Hepatol. 2013; 5 :603-611

(5) Schulze M, Dresske B, Deinzer J, et al. Implication for the usage of the left lateral liver graft for infants $<10 \mathrm{~kg}$, irrespective of a large -for-size situation - are monosegmental grafts redundant ? Transplant Int. $2011 ; 24: 797-804$ 
(6) Carlson GL, Patrick H, Amin Al, et al. Management of the open abdomen: a national study of clinical outcome and safety of negative pressure wound therapy. Ann Surg. 2013;257:1154-9.

(7) Xu HS, Pruett TL, Jones S. Study of donor-recipient liver size match for transplantation. Ann Surg 1994; 219: 46-50.

Table 1. Donor and Receiver characteristics.

\begin{tabular}{lcc}
\hline & \multicolumn{2}{c}{ Patient } \\
\cline { 2 - 3 } Donor & 1 & 2 \\
\cline { 2 - 3 } Weight (kg) & 76 & 68 \\
Height (cm) & 166 & 165 \\
Recipient & & \\
Weight (kg) & 49 & 48 \\
Height (cm) & 145 & 168 \\
Graft weight (g) & 1660 & 1443 \\
GWRW (\%) & 3.38 & 3.01 \\
BSAi & 1.33 & 1.14 \\
Complications & & \\
AST peak (IU & & \\
ALT & 13489 & 145 \\
Clavien-Dindo & 3813 & 3016 \\
NWT (days) & III b & III b \\
Follow-up (Months) & 6 & 4 \\
\hline
\end{tabular}


Figure 1. Patient 1: CT scan at day 14, one month and 6 month after LT, showing the progressive reduction of the peripheral necrosis of anterior and posterior liver sector.

Patient 2: CT scan at day 14, one month and 3 month after LT, showing the progressive reduction of the peripheral necrosis of posterior liver sector.

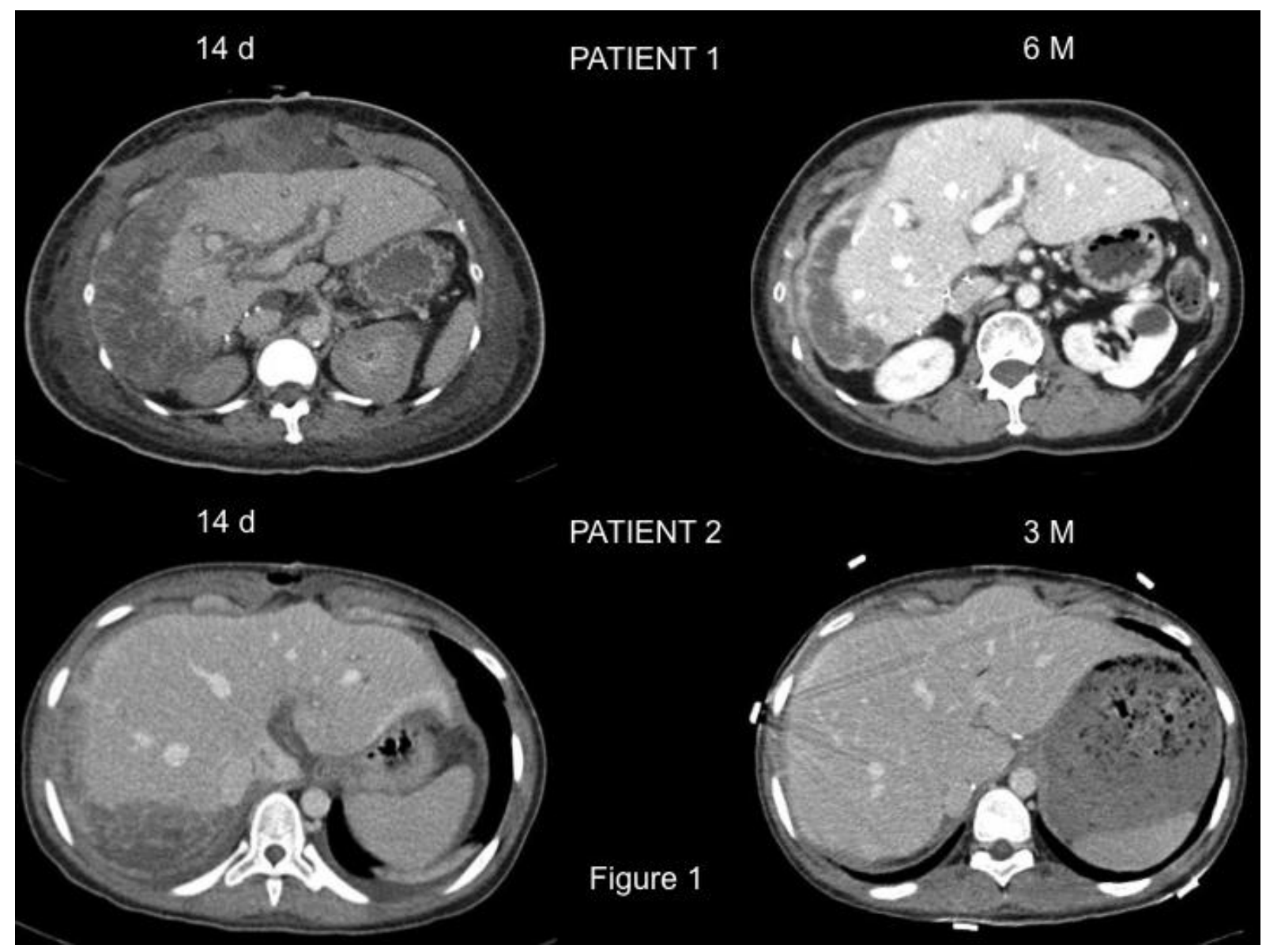

